\title{
APPLICATION OF INFRARED THERMOGRAPHY IN INVESTIGATION OF TRANSVERSAL ROLLING OF STAINLESS STEEL
}

\author{
by Tomasz S. Wisniewski*, Jacek Pawlicki**, Anna Druzycka-Wiencek ${ }^{* * *}$, \\ Franciszek Grosman** and Krzysztof J. Kurzydlowski*** \\ *Institute of Heat Engineering, Warsaw University of Technology, Warsaw, Poland \\ ${ }^{* *}$ Department of Process Modeling and Medical Engineering, Silesian University \\ of Technology, Katowice, Poland \\ ***Materials Science and Engineering Faculty, Warsaw University of Technology, \\ Warsaw, Poland
}

\begin{abstract}
The rolling with transversal rolls movement, one of severe plastic deformation methods, has been performed with use of the patent protected device. This rolling leading to considerable changes of material structure, i.e. decrease of grain size, was applied to samples of 316LVM austenitic steel. It has been observed that transverse rolling of this material is accompanied by significant thermal effect leading to increase of the temperature. In order to control this temperature rise which affects grain size, the temperature measurements were performed with use of ThermaCAM SC 2000 infrared camera.
\end{abstract}

\section{Introduction}

In the recent years intensive research on ultrafine and nanostructure metals and alloys was carried out. The important advantages of such materials are considerably improved mechanical properties and corrosion resistance. Particularly, techniques based on severe plastic deformation (SPD), like cyclic extrusion compression (CEC), hydrostatic extrusion (HE) [1], equal channel angular pressing (ECAP) or high pressure torsion (HPT) have been developed for grain refinement in metals.

Rolling with transversal rolls movement is on of the SPD methods. It ensures relatively large deformation per pass with true strains of an order of 10 . On the other hand it is accompanied by significant thermal effect leading to increase of the temperature which depends on parameters of the process and properties of the material. As a result deformation by rolling may cause dynamic recrystallization of material at relatively low temperature. In these conditions control of the temperature is necessary for obtaining the required structure/properties of the processed materials. On the other hand, thermal effect provides an important information reflecting phenomena that took place during metal forming.

Due to severe plastic deformation and movement of processed material in the transversal rolling application of contact methods for temperature measurement is practically impossible. At the same time infrared thermography gives chance to measure temperature of the material during such forming. 
The subject of this experimental study was the thermal effect related to deformation by transverse rolling process of 316LVM steel. The aim of the measurements was relationship between rolling parameters and microstructure and properties of the material in question.

\section{Experimental}

The rolling with transversal movement has been performed with use of special device $[2,3,4,5]$ that allows for change of rotational speed of rolls, range of transversal movements and their frequency (Fig. 1, 2). The rolling process was applied to Sandvik Bioline 316LVM austenitic steel that is used for medical implants [6]. Chemical composition of 316LVM steel is shown in Table 1. Its standard yield strength $R_{0.2}$ is equal to $430 \mathrm{MPa}$, while tensile strength $R_{m}=740 \mathrm{MPa}$. The original samples were prepared as rectangular bars having dimensions $6 \times 6 \times 100 \mathrm{~mm}$.

This experimental study covered 7 cases of deformation with different rotational speed of rolls ( 3 or $6 \mathrm{rpm})$, amplitude of their transversal movement $(0,0.5$, 1 and $2 \mathrm{~mm}$ ) and frequency ( 1 or $2 \mathrm{~Hz}$ ). In each case 3 passes were executed and during each pass the reduction was equal to $1 \mathrm{~mm}$.

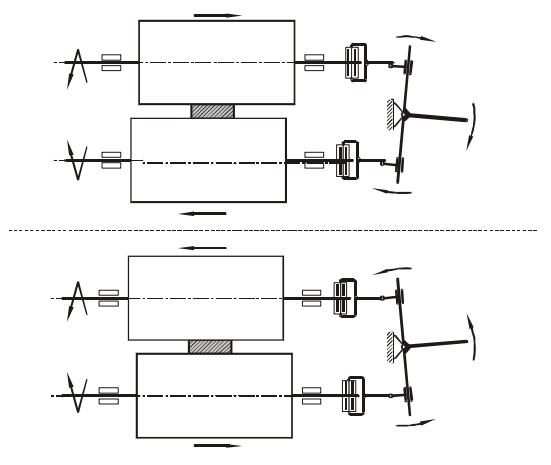

Fig. 1. Principle of rolling with transversal rolls movement

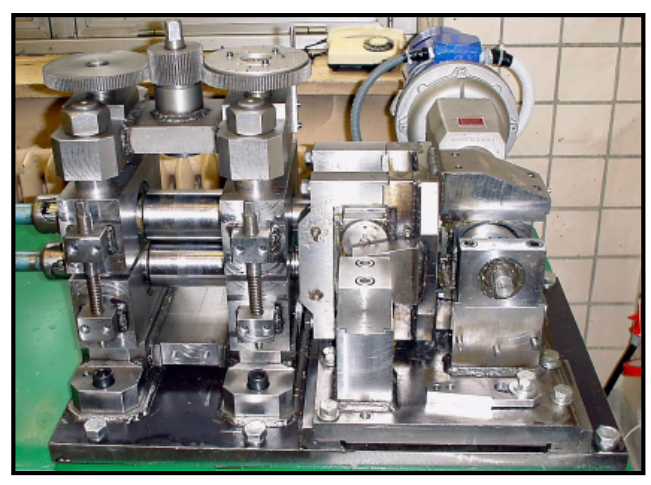

Fig. 2. Rolling device with transversal rolls movement 
http://dx.doi.org/10.21611/qirt.2006.027

Table 1. Chemical composition of $316 L V M$ steel

\begin{tabular}{|l|l|l|l|l|l|l|l|l|l|}
\hline $\mathrm{C}$ & $\mathrm{Si}$ & $\mathrm{Mn}$ & $\mathrm{P}$ & $\mathrm{S}$ & $\mathrm{Cr}$ & $\mathrm{Ni}$ & $\mathrm{Mo}$ & $\mathrm{Cu}$ & $\mathrm{N}$ \\
\hline 0.025 & 0.6 & 1.7 & 0,025 & 0.03 & 17.5 & 13.5 & 2.8 & 0.1 & $<0.1$ \\
\hline
\end{tabular}

Due to considerable deformation and movement of the rolled samples infrared thermography seems to be the only possibility for measurements of temperature during this process. The measurements were performed with use of ThermaCAM SC 2000 infrared camera together with the high speed recording interface and ThermaCAM Researcher 2001 software. The images of rolled products were recorded with frequency of $50 \mathrm{~Hz}$. The samples were covered with soot before rolling. An example of sample after transversal rolling is shown in Figure 3.

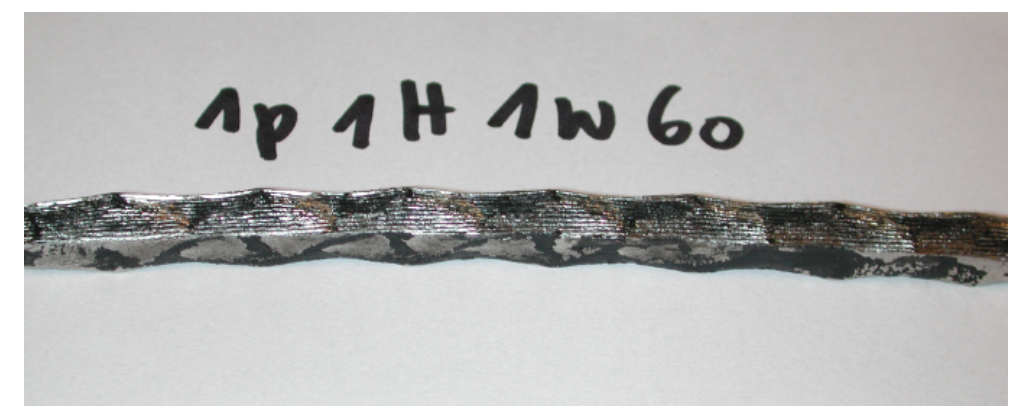

Fig. 3. Sample of stainless steel after transversal rolling

\section{Results and discussion}

Some examples of the results of temperature measurements are shown in Figures 4 and 5 . Figure 5 illustrates temperature rise during subsequent three rolling passes. In this case, the deformation and the temperature rises achieved the highest values. During the first pass temperature of the sample increased to $42^{\circ} \mathrm{C}$. Relatively small temperature rise and short time of rolling resulted from low internal energy (material after soft annealing) and low hardness of the material. In the second pass temperature reached $122^{\circ} \mathrm{C}$ and in the third pass temperature increased to $90^{\circ} \mathrm{C}$.

After each pass the microstructures of rolled samples was investigated. The respective microstructure were compared with the initial before the rolling (Figure 6). The characteristic features of this structure are large amount of re rystallization twins and grains of size over $200 \mu \mathrm{m}$ which are typical of Low Stacking Fault Energy metals.

The microstructure of samples after transversal rolling showed high nonhomogeneity (Figure 7) with clearly developed shear bands. Intensity of these shear bands is influenced by both draft and shearing forces generated by motion of rolls. 
Considerable increase of microhardness of samples subjected to the rolling was observed. In the case of the highest real deformations, average microhardness rised from 206.5 to $436 \mathrm{HV}_{0.2}$.

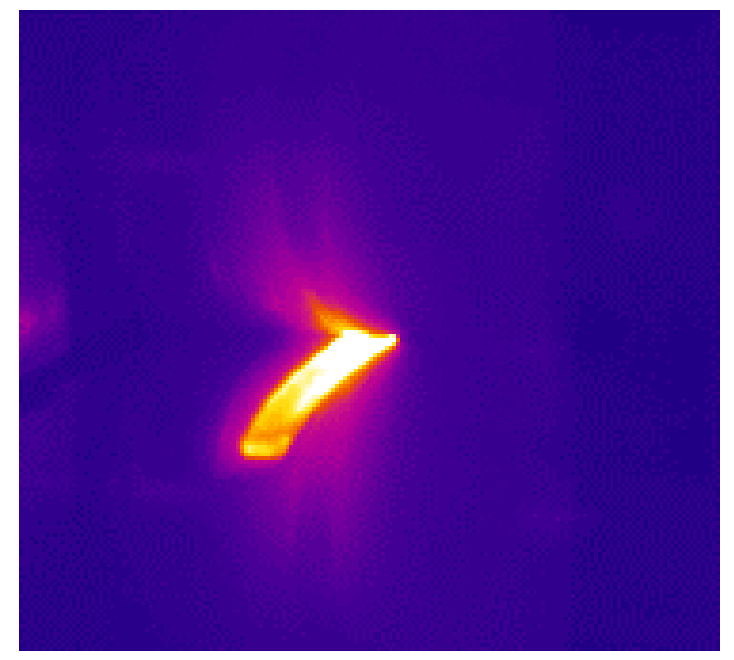

Fig. 4. An example of the IR image of rolled 316LVM steel

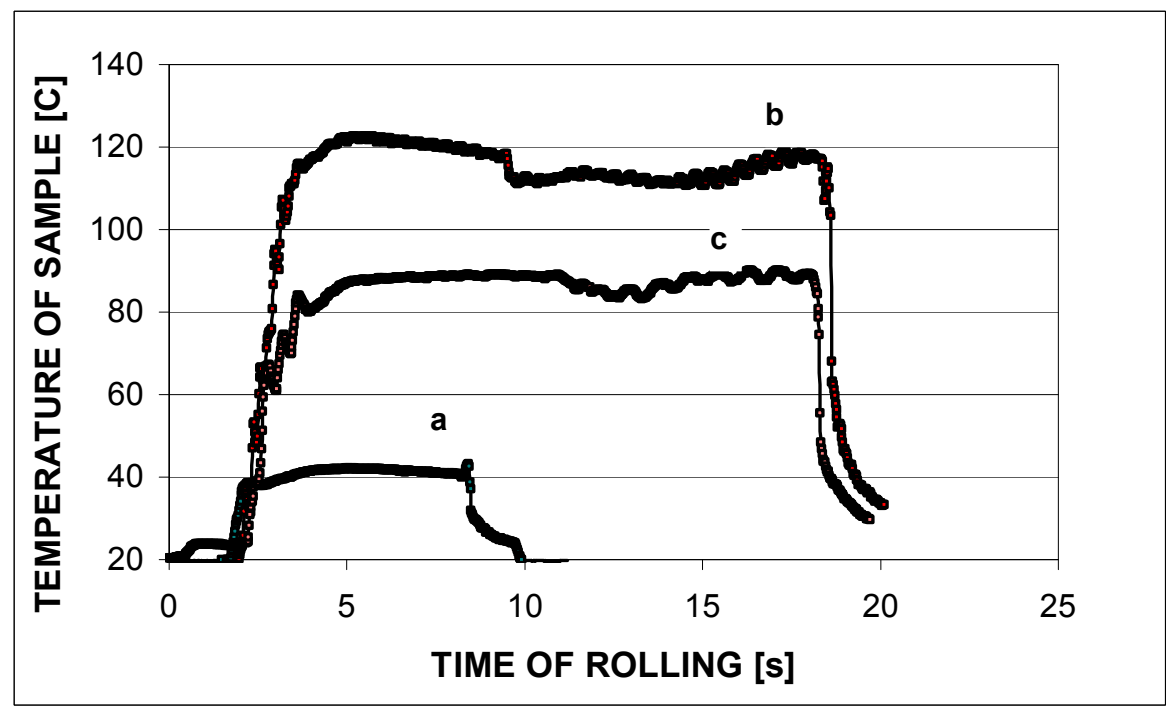

Fig. 5. Temperature rise during subsequent rolling with transversal rolls movement of 316LVM austenitic steel sample; case 1; pass a, b, $c$ 
http://dx.doi.org/10.21611/qirt.2006.027

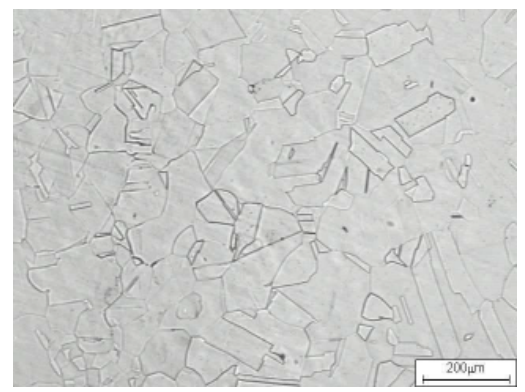

Fig. 6. Microstructure of the material before rolling
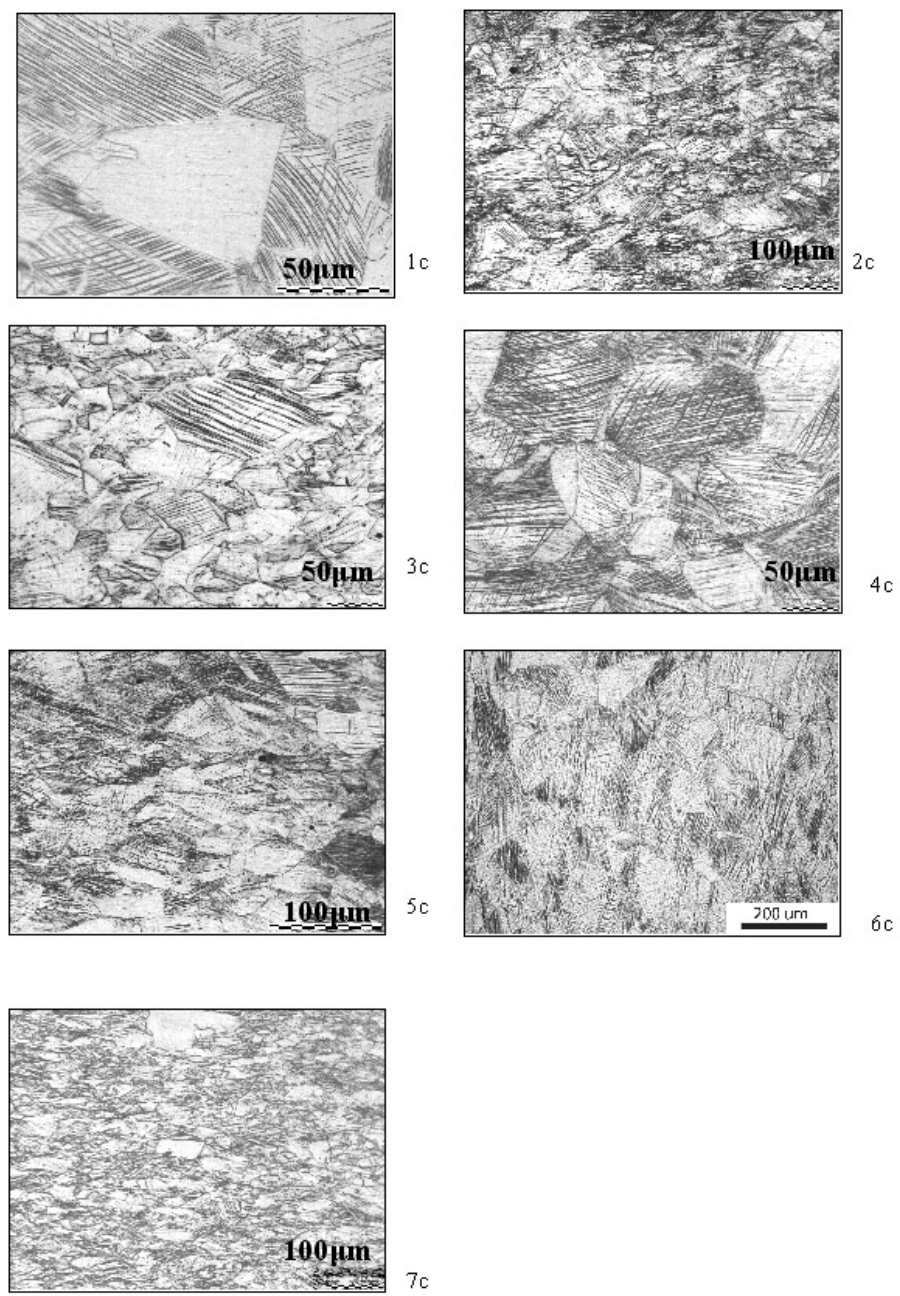

Fig. 7. Microstructures of the samples after third pass for different rolling conditions 


\section{Conclusions}

The results of the study show that a method of transversal rolling is "temperature safe", i.e. allow to avoid temperature rise that could lead to dynamic recristallization and reduce the strength of processed material. Despite the fact the nanostructure was not obtained in the performed series or transversal rollings, considerable decrease of grain size was attained. This opens perspectives for this metal forming method to be commercially valuable grain refinement process.

The infrared thermography can be successfully utilized for measurements of the temperature rise during metal forming by severe plastic deformation. The information on thermal effects is necessary both for analysis of undergoing phenomena and design of SPD methods for grain refinement.

\section{REFERENCES}

[1] Kong L.X., Lin L., Hodgson P.D.: Material properties under drawing and extrusion with cyclic torsion. Materials Science and Engineering, A308, 2001, pp. 209-215.

[2] Grosman F., Pawlicki J.: Concepts of technological applications in controlled deformation of materials. Acta Metallurgica Slovaca, R.8, 1/2002, pp. 178-182.

[3] Bochniak W., Korbel A.: KOBO Type Forming: forging of metals under complex conditions of the process. Journal of Materials Processing Technology, vol. 134, 2003, pp. 120-134.

[4] Grosman F., Pawlicki J.: Concepts of technological applications in controlled deformation of materials. Procedings of the $7^{\text {th }}$ International Conference on Technology of Plasticity, Advanced Technology of Plasticity, Yokohama, Japan, vol.1, 2002, pp. 1219-1224.

[5] Patent P-361148.

[6] E. Wallen, O. Sundqvist, Cleanliness of vacuum-arc remelted 316LVM, Paper presented at Semicon Southwest, Austin Texas USA, October 14-15, 1997

\section{Acknowledgment}

This work was supported by the Ministry of Scientific Research and Information Technology under grant No 3T08A 06528. 